Carlos de Sousa $\mathrm{LUCCl}^{1}$ Edison VALVASORI ${ }^{2}$ Adriana CAPEZZUTO ${ }^{1}$ Ricardo LOPES $^{1}$ Valter FONTOLAN ${ }^{1}$ Gilberto BUFFARAH ${ }^{2}$ Kleber da Cunha PEIXOTOJUNIOR ${ }^{1}$

Correspondência para: CARLOS DE SOUSA LUCCI Faculdade de Medicina Veterinária Universidade de Santo Amaro R. Manuel de Paiva Ramos, 60 - apto. SR-54 05351-015 - São Paulo - SP cslucci@uol.com.br

Recebido para publicação: 30/08/2004 Aprovado para publicação: 13/07/2005

\title{
Digestibilidade in situ de cana de açúcar (Saccharum officinarum) nas formas natural ou ensilada, adicionadas ou não de uréia
}

\author{
1 - Faculdade de Medicina Veterinária da Universidade de Santo Amaro, \\ São Paulo - SP \\ 2 - Instituto de Zootecnia da Secretaria da Agricultura de São Paulo, \\ São Paulo - SP
}

\section{Resumo}

Doze ovinos com cânulas de rúmen foram empregados para comparar seis tratamentos, dispostos em um arranjo fatorial $2 \times 3$ : cana de açúcar nas formas fresca (CAF) ou ensilada (CAS) x teores de uréia iguais a $0,0 \%, 0,5 \%$ e $1,0 \%$. Foram estimadas: taxas de degradabilidade efetiva (DGE) dos alimentos volumosos, concentrações de ácidos graxos voláteis(AGV) e de nitrogênio amoniacal (N-NH3) e valores de $\mathrm{pH}$ do conteúdo do rúmen, além de concentrações de N-uréico no sangue. As taxas de DGE da matéria seca (MS) mostraram-se semelhantes para CAF e CAS. A adição de teores crescentes de uréia às forragens resultou em diminuição linear da DGE da MS tanto da CAF como da CAS. No caso da CAS, a DGE da fibra em detergente neutro diminuiu linearmente com concentrações crescentes de uréia. Os valores de $\mathrm{pH}$ do conteúdo ruminal foram maiores para CAS em relação a CAF, mas não ocorreram diferenças devidas à adição de uréia. Os teores do conteúdo ruminal em total de AGV e os de ácido propiônico foram maiores para a CAF em relação a CAS; os de ácido acético, ao contrário, foram maiores para a CAS. Os teores de N-NH3 do conteúdo ruminal foram maiores para a CAS que para a CAF. Nos tratamentos com CAF e nos com CAS, as concentrações de N-NH3 no conteúdo ruminal e de $\mathrm{N}$-uréico no sangue aumentaram linearmente com maiores adições de uréia. Concluiu-se que a adição de $0,5 \%$ e 1,0\% uréia às forragens frescas ou ensiladas de cana-deaçucar não mostrou resultados satisfatórios e que CAF apresentou indícios de melhor qualidade nutricional que CAS.

\section{Introdução}

A cana-de-açúcar tem se destacado na alimentação de ruminantes por seu alto valor energético como também por apresentar custo operacional com máquinas e operações inferior aos de forragens como milho ou sorgo. Tendo elevado teor sacarose, esta forragem é considerada de bom valor nutritivo para bovinos ${ }^{1,2,3}$, desde que adequadamente corrigida em suas deficiências tais como as concentrações de minerais e de nitrogênio ${ }^{4}$ e de amido $^{5,7}$. Trabalhos de digestiblidade com cana-de-
Palavras-chave: Cana-de-açúcar. Silagem de cana de açúcar. Degradabilidade ruminal. açúcar como alimento base de dietas para ruminantes, evidenciaram dependência dos teores dietéticos de nitrogênio para aproveitamento adequado do alimento. Maiores taxas de digestibilidade da matéria seca foram direta e positivamente relacionadas à qualidade e quantidade de suplemento nitrogenado incluído nas rações $^{7,8,9}$, fato devido à digestão no rúmen depender da interação energia - nitrogênio ${ }^{10}$. Autores ${ }^{9}$ suplementando dietas a base de cana-de-açúcar com farelo de algodão encontraram no conteúdo do rúmen valores de N-NH3 iguais a 11,19 mg./dl; outros 
pesquisadores ${ }^{11}$ suplementando cana-deaçúcar com amido constataram concentrações de $\mathrm{N}$ - NH3 entre 4,2 a 4,9 $\mathrm{mg} \mathrm{N}-\mathrm{NH} 3 / \mathrm{dl}$. O valor de $5 \mathrm{mg} / \mathrm{dl}^{12}$ tem sido adotado como suficiente para garantir boa fermentação ruminal.

Vários autores ${ }^{13,14}$ chamaram a atenção para os baixos índices de degradabilidade deste alimento no rúmen. Foram encontradas taxas de degradabilidade efetivas iguais a $35,9 \%$ para a matéria seca $(\mathrm{MS})^{15}$, médias de degradabilidade efetiva de $63,9 \%$ para a MS e de $24,6 \%$ para a fibra em detergente neutro $(\mathrm{FDN})^{16}$. Em pesquisa onde foram adicionadas quantidades de até $2,0 \%$ de uréia a uma dieta com $85 \%$ de cana e $15 \%$ de farelo de algodão ${ }^{17}$, não foram constatadas alterações na digestibilidade ruminal e registraram-se valores de degradabilidade efetiva da cana entre $53,5 \%$ e 55,8\% para MS e entre $23,9 \%$ a $26,9 \%$ para $\mathrm{FDN}^{17}$. Outros valores de respectivamente $51,3 \%$ e $25,5 \%$ para a degradabilidade da MS e FDN da cana-deaçúcar também foram registrados ${ }^{8}$.

Alterações provocadas pelo emprego da cana-de-açúcar na alimentação de ruminantes mereceram o destaque que rações ricas neste alimento, com teores elevados de carboidratos prontamente fermentescíveis podem deprimir a digestão da celulose e o consumo de $\mathrm{MS}^{18}$. Estas mesmas dietas aumentariam a quantidade e disponibilidade de ácidos graxos voláteis (AGV), com acréscimo nas concentrações dos ácidos propiônico e butírico ${ }^{19}$. Neste particular foram encontrados valores de AGV iguais a $68,8 \%, 21,7 \%$ e $9,5 \%$ para os ácidos acéticos, propionico e butírico respectivamente', e ainda teores de AGV totais entre 128 e $173 \mathrm{mmol}$. por litro de liquido ruminal ${ }^{20}$, ambos os trabalhos com dietas a base de cana-de-açúcar.

Quanto ao pH do conteúdo ruminal, experimentos mostraram valores variando de 6,0 a $7,3^{11,13,21,22,23}$.

A administração de cana-de-açúcar como suplemento volumoso durante o período de estiagem, na região do Brasil central, é prática comum. A ensilagem, pela facilidade de preparo e de armazenamento próximo aos grandes lotes de animais, surge como alternativa a alimentação com cana in natura, apesar de registros da literatura relatarem sua qualidade como inferior a da forragem fresca ${ }^{24}$.

O objetivo do presente trabalho foi comparar a cana-de-açúcar nas formas natural ou ensilada, bem como os fatores de acréscimo ou não de uréia, por meio de estimativa de degradabilidade efetiva e de metabolitos do conteúdo ruminal.

\section{Materiais e Métodos}

A degradabilidade MS da cana-deaçúcar como ingrediente de rações para ovinos, foi avaliada pela técnica dos sacos de náilon "in situ" "25. Determinaram-se também as concentrações de ácidos graxos voláteis (AGV), nitrogênio amoniacal (N$\mathrm{NH} 3$ ), e valores de $\mathrm{pH}$ de amostras de conteúdos ruminais, além de teores de uréia sanguínea. Foram empregados 12 ovinos machos da raça Suffolk, com cânulas de rúmen, tendo idade variando entre um e dois anos. O delineamento experimental foi em blocos ao acaso $^{26}$, comparando seis tratamentos, em disposição fatorial $2 \times 3$ : cana ensilada (CAS) e cana como forragem fresca (CAF), e três teores de adição de uréia: $0,0 \%, 0,5 \%$ e $1,0 \%$, acrescidos à forragem no momento de ensilar ou, para a forma fresca, imediatamente antes de sua administração. As dietas foram balanceadas para teores semelhantes de nitrogênio, com emprego de farelo de soja (45\% de proteína bruta) de forma idêntica para cana fresca ou silagem. Ambos volumosos foram ingeridos em quantidades pré-fixadas individualmente como $80 \%$ do consumo ad libitum, com média de $2,0 \mathrm{~kg}$ de matéria original/cabeça/dia. Procurou-se atender as exigências nutricionais em nitrogênio conforme NRC, $1985^{27}$.

A cana-de-açúcar foi administrada picada em partes semelhantes às daquelas apresentadas pela silagem, de 2,0 cm em 
média. A ração foi fornecida duas vezes ao dia, como mistura única de volumoso concentrado.

Estimativas de degradabilidade efetiva ruminal da MS da forragem fresca e da silagem de cana-de-açúcar foram obtidas de animais que recebiam os volumosos correspondentes, empregando-se a técnica dos sacos de náilon in situ. Os sacos de náilon apresentavam porosidade de $50 \mu \mathrm{m}$, medindo $10,0 \times 20,0 \mathrm{~cm}$, e receberam por volta de 5,0 g em matéria original de amostras de cana, como forragem ou como silagem, imitando a forma em que eram fornecidas aos animais inclusive nas quantidades de $0 \%$ ou $0,5 \%$ ou $1,0 \%$ de uréia. Os tempos de incubação foram de 0 , $6,12,24,72$ e 96 horas, a partir do fornecimento do alimento. As análises bromatológicas da MS e proteína bruta (PB) seguiram as técnicas descritas pela AOAC, $1984^{28}$, sendo a FDN analisada conforme Goering e Van Soest, 197029. Os dados de degradabilidade foram ajustados pelo modelo de Orskov e McDonald, 1979², e as degradabilidades efetivas (dge) seguiram a equação de Orskov, Hovell e Mould, ${ }^{25}$ adotando-se taxa de passagem $r=0,2$. No dia seguinte a retirada dos sacos do interior do rúmen, fez-se coleta do líquido ruminal, nos tempos de $0,1,2,3,4,6,8$ e 24 horas após a alimentação, para análises das concentrações de AGV (colheita de 4 horas), de N-NH3 (colheitas de 1 e $2 \mathrm{~h}$ ), e determinação dos valores de $\mathrm{pH}$ (colheitas de 0,1 e 2 horas), e ainda para determinação da cinética líquida do rúmen, através da administração de polietilenoglicol peso molecular 4000 ${ }^{31}$. Coletas de sangue prestaram-se para estudar concentrações de $\mathrm{N}$ uréico sérico, sendo coletadas amostras três horas após a primeira alimentação do dia .A mensuração dos AGV dos líquidos ruminais nos tratamentos com a cana-deaçúcar, ensilada e "in natura", foi realizada através de cromatografia gasosa de acordo com a metodologia empregada por Erwin, Marco e Emery ${ }^{32}$. A análise estatística foi executada conforme programa do SAS, ${ }^{33}$ considerando-se significativas às diferenças que atingiram probabilidade de 5\% e pesquisando-se a linearidade nas respostas às concentrações de uréia dos diferentes tratamentos.

\section{Resultados e Discussão}

Os teores de PB encontrados para amostras dos alimentos volumosos (Tabela 1) mostram aumentos para a forragem de $280 \%$ e $420 \%$, e para a silagem, de $220 \%$ e $360 \%$ respectivamente para os acréscimos de $0,5 \%$ e $1,0 \%$ de uréia, em relação à forragem sem adição de uréia.

Detectaram-se maiores teores de extrativos não nitrogenados e, portanto de açúcares solúveis, favorecendo a forragem fresca $(65,2 \%$ a $73,4 \%)$ em relação à silagem $(46,3 \%$ a $57,2 \%)$, provavelmente devido à utilização dos açucares no processo de ensilagem.

Houve equilíbrio nas ingestões de nitrogênio pelos animais, calculando-se quantidades de equivalentes protéicos de 116,1g, 109,6g e 99,2g nos tratamentos com silagem, e de 115,8g, 103,7g e 93,1 g nos com cana-de-açúcar, quando adicionados respectivamente de $0,0 \%, 0,5 \%$ e $1,0 \%$ de uréia, inseridas as quantidades fornecidas pela adição de farelo de soja.

As concentrações de N-NH3 do conteúdo ruminal foram significativamente mais elevadas para os ovinos alimentados com silagem, em relação aos que receberam forragem fresca, nos tempos $1 \mathrm{~h}(\mathrm{p}=0,005) \mathrm{e}$ $2 \mathrm{~h}$ pós-refeição $(\mathrm{p}=0,038)$. Os valores das concentrações de N-NH3 nos conteúdos ruminais aumentaram linearmente com maiores níveis de uréia alimentar, tanto para silagem ( $p=0,000$ para $1 \mathrm{~h}$ e $2 \mathrm{~h}$ pósrefeição) como no caso da forragem fresca ( $\mathrm{p}=0,003$ para $1 \mathrm{~h}$ e $\mathrm{p}=0,007$ para $2 \mathrm{~h}$ pósrefeição). Provavelmente os aumentos em N-NH3 do conteúdo ruminal foram maiores para silagens pelo fato destas apresentarem maiores teores de $\mathrm{N}$ não protéico, mesmo antes das adições de uréia, aliando-se a isso menores teores de 
Tabela 1 - Composição química da cana-de-açucar e silagem de cana-de-açucar, com 0,0\%, 0,5\% ou 1,0\% de areia acrescida. Resultados em porcentagens na matéria seca isenta de umidade. Ingestões de equivalente protéico (EP) em g/anima/dia. Nova Odessa, SP, 2001

\begin{tabular}{ccccccc}
\hline & CAS & CAS & CAS & CAF & CAF & CAF \\
\hline uréia & $0,0 \%$ & $0,5 \%$ & $1,0 \%$ & $0,0 \%$ & $0,5 \%$ & $1,0 \%$ \\
MS & 19,45 & 20,16 & 21,45 & 27,30 & 26,32 & 26,57 \\
MM & 5,84 & 5,97 & 5,23 & 2,69 & 2,63 & 2,60 \\
FDN & 35,36 & 33,94 & 36,06 & 23,99 & 24,30 & 23,47 \\
PB & 4,34 & 12,31 & 18,36 & 3,15 & 7,07 & 11,56 \\
ENN & 52,63 & 46,39 & 57,20 & 69,45 & 65,24 & 73,47 \\
EE & 1,50 & 1,40 & 1,50 & 0,73 & 0,77 & 0,65 \\
EP & 116,1 & 109,6 & 99,2 & 115,8 & 103,7 & 93,1 \\
\hline
\end{tabular}

$\mathrm{CAS}=$ silagem de cana-de-açucar; $\mathrm{CAF}=$ cana-de-açucar; $\mathrm{MS}=$ matéria seca; $\mathrm{MM}=$ matéria mineral; $\mathrm{FDN}=$ fibra em detergente neutro; $\mathrm{PB}=$ proteína bruta; $\mathrm{ENN}=$ estrativo não nitrogenado; $\mathrm{EE}=$ extrato etéreo

carboidratos solúveis, em relação ao alimento não ensilado. Preston, ${ }^{4}$ já chamara a atenção para o fato da forragem, fresca ou ensilada, ser pobre em nitrogênio, daí a preocupação em que este nutriente não falte nas rações à base de cana-de-açúcar. Contudo, os resultados obtidos em N-NH3 no líquido ruminal foram superiores ao esperado, notadamente no caso da silagem. Para a forragem fresca, as concentrações de $\mathrm{N}-\mathrm{NH} 3$ no líquido do rúmen, em mg./dl, foram de 1,8 a 5,2 para o nível zero, de 11,0 a 22,9 para o nível $0,5 \%$ e de 14,2 e 31,2 para o nível 1,0\% de uréia. Resultados experimentais encontraram média de 11,1 $\mathrm{mg} / \mathrm{dl} \mathrm{em} \mathrm{dietas} \mathrm{de} \mathrm{cana} \mathrm{de} \mathrm{açúcar} \mathrm{mais}$ farelo de algodão ${ }^{9}$, mas outros ${ }^{11}$ registraram para dieta semelhante, porém acrescida de amido, valores entre 4,2 a 4,9 mg/dl. Segundo alguns pesquisadores ${ }^{12}$ seriam suficientes $5 \mathrm{mg} / \mathrm{dl}$ para garantir boa fermentação ruminal, embora outros ${ }^{34}$ tenham relatado que concentrações entre 19 a $23 \mathrm{mg} / \mathrm{dl}$ seriam mais recomendáveis para a digestão ruminal de dietas fibrosas.

Houve aumento linear do $\mathrm{N}$ ureico do sangue com incremento das taxas de uréia na alimentação tanto para silagem $(\mathrm{p}=0.004)$ como para cana fresca $(p=0,004)$, fato condizente com a elevação dos teores de N-NH3 encontrados no conteúdo do rúmen.

As médias das concentrações dos ácidos graxos voláteis (AGV) acético, propiônico e butírico, em porcentagens no líquido ruminal, as dos totais dos $A G V$, em micromoles por litro $(\mathrm{mM})$, acusam diferenças significativas nos totais de AGV, com valores superiores para a cana in natura em relação à silagem. $(p=0,037)$. Isto pode ter ocorrido pela maior disponibilidade de carboidratos na forragem fresca relativamente à silagem, propiciando fermentação mais intensa dos alimentos pelas bactérias ruminais ${ }^{10}$. As porcentagens de ácido acético foram significativamente superiores na silagem $(p=0,004)$ e as de ácido propiônico, ao contrário, significativamente maiores $(p=0,002)$ na forragem fresca, um ponto positivo para este tratamento já que o ácido propionico possue capacidade de gluconeogenese ${ }^{10}$.

As degradabilidades efetivas da MS dos volumosos foram semelhantes para silagem de cana e cana-de- açúcar $(\mathrm{p}=$ 0,4057). A degradabilidade da FDN das silagens diminuiu de forma linear ( $Y=31,33$ $-8,576 x$ ) com o emprego de maiores níveis de uréia dietéticos. Uma das explicações para este fato seria menor disponibilidade de energia no rúmen, na forma de amido, para suportar melhor aproveitamento do N-NH3 ruminal. A degradabilidade da MS nos tratamentos com silagens, mais elevada nas rações sem adição de uréia, teria possível explicação na quantidade mais alta de $\mathrm{PB}$ 
Tabela 3 - Degradabilidade efetiva da matéria eca (MS) da silagem de cana-de-açucar (CAS) e da cana-de-açucar (CAF), em porcentagens, valores de $\mathrm{pH}$, e valores de cinética de líquido ruminal : taxas de passagem em porcentagens por hora, turn-over por 24 horas e volumes líquidos do rúmen em litros. Nova Odessa, SP, 2001

\begin{tabular}{lllllllll}
\hline & CAS-0 $\%$ & $\begin{array}{l}\text { CAS- } \\
0,5 \%\end{array}$ & $\begin{array}{l}\text { CAS- } \\
1,0 \%\end{array}$ & MÉDIA & CAF-0 $\%$ & CAF- & CAF- & MÉDIA \\
& & & & $0,5 \%$ & $1,0 \%$ & \\
\hline N-NH3-1h & 15,36 & 33,78 & 39,96 & 47,858 & 5,23 & 28,82 & 26,81 & 20,29 \\
N-NH3-2h & 14,93 & 30,29 & 37,64 & 27,62 & 4,13 & 28,82 & 31,21 & 19,42 \\
Nureiasoro & 12,32 & 27,84 & 36,44 & 25,60 & 8,00 & 24,72 & 33,12 & 21,95 \\
Ac.CC & 85,590 & 75,262 & 53,016 & 71,289 & 60,681 & 56,349 & 72,325 & 63,118 \\
Ac.CCC & 12,430 & 19,948 & 11,539 & 14,639 & 28,609 & 36,631 & 25,323 & 30,188 \\
Ac. CCCC & 1,980 & 4,790 & 10,445 & 5,738 & 10,710 & 7,020 & 2,351 & 6,694 \\
AGVtotal & 36,623 & 48,149 & 47,858 & 44,210 & 49,320 & 63,020 & 44,137 & 52,159 \\
\hline
\end{tabular}

(a): $Y=31,33-8,576 X ;(b): Y=41,96-5,79 X ;(c)^{*} Y=43,13-10,15 X$

$\mathrm{pH} 1 \mathrm{~h}$ silagem 6,71 > cana 6,32 $(\mathrm{p}=0,002)$

$\mathrm{pH} 2 \mathrm{~h}$ silagem 6,59 > cana 6,33 ( $\mathrm{p}=0,027)$

Tabela 2 - Valores de nitrogênio amoniacal ( N-NH3) do conteúdo ruminal, 1 he 2 h pós primeira refeição, valores das concentrações de N ureico sérico (mg/dl) e das concentrações porcentuais dos ácidos graxos voláteis ( AGV ) acetico, propionico e butírico

\begin{tabular}{ccccccc}
\hline & Reg linear & $\mathrm{Y}$ & CAS-0,0\% & CAS-0,5 & CAS-1,0 & MÉDIA \\
\hline FDN(dge) & $\mathrm{P}=0,01$ & (a) & 33,14 & 23,45 & 24,57 & 27,05 \\
MS(dge) & $\mathrm{P}=0,03$ & (b) & 42,36 & 38,28 & 36,56 & 39,40 \\
pH-0h & & N.S. & 6,96 & 6,95 & 6,62 & 6,85 \\
PH-1h & & N.S. & 6,63 & 6,80 & 6,69 & 6,71 \\
PH-2h & N.S. & 6,56 & 6,69 & 6,54 & 6,59 \\
Tx.passagem & & 4,037 & 5,980 & 5,676 & 5,231 \\
Turn-over & & 0,970 & 1,435 & 1,362 & 1,256 \\
Vol rumen & & 11,941 & 13,152 & 8,824 & 11,306 \\
& & & & & \\
& & & CAF-0,0\% & CAF-0,5\% & CAF-1,0\% & MÉDIA \\
MS(dge) & $\mathrm{P}=0,02$ & (c) & 39,810 & 44,700 & 29,654 & 38,055 \\
PH-0h & & 6,68 & 6,67 & 6,65 & 6,67 \\
PH-1h & & 6,21 & 6,17 & 6,59 & 6,32 \\
PH-2h & & 6,28 & 6,18 & 6,53 & 6,33 \\
Tx passagem & & 5,242 & 7,170 & 6,405 & 6,273 \\
Turn-over & & 1,258 & 1,721 & 1,537 & 1,505 \\
Vol.rumen & & 12,121 & 1,721 & 11,465 & 12,195 \\
\hline
\end{tabular}

$\mathrm{N}-\mathrm{NH} 3$ para $1 \mathrm{~h}$ após :

$\mathrm{CAS}=29,70>\operatorname{CAF} 20,29(\mathrm{p}=0,005)$

Níveis d. CAS $=$ reg linear $(p=0,000) 0 \%=15,36 ; 0,5 \%=33,781,0=39,96$

Níveis d. CAF $=$ reg linear $(p=0,003) 0=5,23 ; 0,5=28,82 ; 1,0=24,81$

$\mathrm{N}-\mathrm{NH} 3$ para 2 horas após:

$\mathrm{CAS}=27,62>\operatorname{CAF} 19,42(\mathrm{p}=0,038)$

Níveis d. CAS: reg linear $(p=0,000) 0=14,93 ; 0,5=30,29 ; 1,0=37,64$

Níveis d. CAF : reg linear $(p=0,007) 0=4,13 ; 0,5=22,94 ; 1,0=21,21$ 
verdadeira nos tratamentos do volumoso não adicionado de uréia. Os valores de degradabilidade efetiva da MS da silagem apresentaram média de $52,3 \%$, e os da canade-açúcar, $47,9 \%$, resultados comparáveis aos de outros pesquisadores ${ }^{17,35}$, contudo ficam aquém dos obtidos por Aroeira et al. ${ }^{16}$ de $63,9 \%$ e superiores ao valor de $35,9 \%$ obtido por Valadares Filho et al. ${ }^{15}$

As médias de $\mathrm{pH}$ do líquido ruminal nos diferentes tempos de coleta e tratamentos apresentaram valores mais elevados para silagem, entre 6,59 a 6,85 , em relação aos com forragem fresca. entre 6,32 a $6,67(\mathrm{p}=$ 0,002 e $\mathrm{p}=0,027$ para $1 \mathrm{~h}$ e $2 \mathrm{~h}$ pós-refeição respectivamente).Estes resultados são condizentes com os obtidos para as concentrações de AGV, maiores para a cana in natura, e os valores de N-NH3 do conteúdo ruminal, superiores para a silagem. Diferenças em $\mathrm{pH}$ indicam populações bacterianas desiguais, o $\mathrm{pH}$ mais elevado favorecendo maior presença de bactérias celuloliticas ${ }^{36,37}$. Essa suposição é sustentada pelas maiores proporções de acido acético obtidas com silagem, e de acido propionico, com cana in natura. Para o $\mathrm{pH}$ do líquido ruminal em animais recebendo cana-deaçúcar, vários autores ${ }^{11,13,21,22,23}$ mostraram números variando de 6,0 a 7,3. Dada à riqueza da cana em carboidratos solúveis, seriam esperados valores baixos de $\mathrm{pH}$ de conteúdo ruminal ${ }^{18}$. Contudo alguns autores explicam que a alta taxa de fluxo salivar devida ao alto teor de fibra bruta da cana age tamponando os produtos de fermentação do açúcar, e a ação de protozoários ciliados ingerindo e estocando açúcares em seus organismos de forma a torná-los temporariamente indisponíveis no substrato para a fermentação bacteriana, impedem a produção de um $\mathrm{pH}$ menor no conteúdo do rúmen. ${ }^{38,39,40}$

Os resultados encontrados para o volume de líquido ruminal, em litros, taxa de passagem e o fluxo de líquido em 24 horas não mostraram diferenças significativas entre volumosos.

\section{Conclusões}

Nas condições deste experimento, em rações isonitrogenadas e comingestões pré-fixadas de alimentos, as seguintes conclusões podem ser enumeradas:

1. Os teores do conteúdo ruminal em AGV totais e acido propionico, bem como os teores de extrativos não nitrogenados nos alimentos, todos maiores para a forragem fresca que para a ensilada, indicam melhor valor nutricional da forragem fresca.

2. A adição de níveis crescentes de uréia nas forragens não apresentou resultados suficientemente satisfatórios para permitir sua indicação.

\section{In situ digestibility of sugar-cane (Saccharum officinarum) as fresh forage or silage, with or without urea}

\section{Abstract}

Twelve rumen canulated male sheep were used to evaluate ruminal effective degradability (EDG) and volatile fatty acids(VFA), ammonia nitrogen $(\mathrm{N}-\mathrm{NH} 3)$ and $\mathrm{pH}$ of rumen contents, and blood ureic nitrogen. They received six treatments in a factorial arrangement $2 \times 3$ : sugar cane fresh (CAF) or as silage (CAS) x urea levels of $0 \%, 0.5 \%$ and $1.0 \%$ for both forages. Values of EDG of CAF and CAS dry matter(DM) were not significantly different. Addition of crescent levels of urea to the forages resulted in a linear decrease of DM EDG for CAF and CAS. Considering CAS, EDG of neutral detergent fiber was linearly lower with crescent levels of urea. Ruminal contents $\mathrm{pH}$ values were higher for CAF than for CAS but no differences were find among levels of urea addition. Ruminal contents levels of total
Key-words:

Sugar-cane.

Sugar-cane silage.

Ruminal degradability. 
VFA and propionic acid were higher for CAF than for CAS; inversely, acetic acid levels were higher for CAS. N-NH3 levels of ruminal contents were higher for CAS than for CAF. For both fresh and silage treatments, $\mathrm{N}-\mathrm{NH} 3$ concentrations in ruminal contents, as well $\mathrm{N}$-ureic blood concentrations increased linearly with higher levels of urea addition. It was concluded that $0.5 \%$ and $1.0 \%$ urea added to fresh or ensiled forages had no satisfactory results and that CAF indicated better nutritional value than CAS.

\section{Referências}

1 NOGUEIRA FILHO, F. C. M., et al. Estudo comparativo entre cana-de-açúcar e silagens de milho, sorgo e capim Napier na alimentação de vacas leiteiras. B. Indústr. Anim. v. 34, n. 1, p. 75-84,1977.

2 BIONDI, P. et al. Substituição parcial e total da silagem de milho por cana-de-açúcar como únicos volumosos para vacas em lactação. B. Indústr. Anim. v. 35, n. 1, p. $45-55,1978$.

3 VALVASORI, E. Avaliação da cana-de-açúcar em substituição à silagem de milho para vacas leiteiras. Braz. J. Vet. Res. Anim. Sci. v. 32, n. 4, p. 224-228, 1995.

4 PRESTON, T. R. Nutritive value of sugar cane for ruminants. Trop. Anim. Prod. v. 2, n. 2, p. 125-42, 1977.

5 BOIN, C.et al. Comparação entre silagem de milho e cana-de-açúcar na alimentação de ruminantes. Efeito da suplementação de uréia na produção de leite. In: Reunião anual da Sociedade Brasileira de Zootecnia, 20.,1983, Pelotas. Anais...Pelotas: SBZ, 1983, a. p. 81

6 BOIN, C. et al. Comparação entre silagem de milho e cana-de-açúcar na alimentação de ruminantes: Efeito do nível de concentrado. In: Reunião Anual Sociedade Brasileira de Zootecnia 20.,1983, Pelotas. Anais... Pelotas: SBZ, 1983b. p. 80,85.

7 PEREIRA, O. G. et al. Degradabilidade in vivo e in situ de nutrientes e eficiência de síntese de proteína microbiana, em bovinos, alimentados com cana-deaçúcar sob diferentes formas. R. Soc. Bras. Zoot. v. 25, n. 4, p. 763-777, 1996.

8 AROEIRA, L. J. M. Digestibilidade, degradabilidade e taxa de passagem da cana-de-açúcar mais uréia e do farelo de algodão em vacas mestiças Holandês X Zebu em Lactação. R Soc Bras Zoot, v. 24, n. 6, p. 10161026, 1995

9 LUDOVICO, A, MATTOS, W. R. S. Avaliação de dietas a base de cana-de-açúcar (Sacharum officinarum L) e diferentes níveis de semente de algodão (Gossyplum hirsutum L. ). R Soc Bras Zoot, v. 26, n. 2, p. 403-10, 1997.

10 NOCEK, J. E. In situ and other methods to estimate ruminal protein and energy digestibility: a review. J. Dairy Sci. v. 71, n. 10, p. 2051-2069, 1988.
11 ELLIOTT, R.et al. Rice polishings as a supplement in sugar cane diets: the quantities of starch (aa-linked glucose polymers) entering the proximal duodenum. Trop Anim Prod, v. 3, n. 1, p. 30-35, 1978.

12 SATTER, L. D.; SLYTER, L. L. Effect of ammonia concentration on rumen microbial protein production in vitro. Br. J. Nutr. v. 32, n. 2, p. 199-208, 1974.

13 RAVELO, G.; GONZALES, F.; HOVELL, F. D. El efecto de alimentar por fístula ruminal canã de azúcar e airecho de trigo sobre el consumo de canã de azúcar. Prod. Anim. Trop. v. 3, n. 3, p. 237-242, 1978.

14 ORSKOV, W. R., HOVELL, D. D. Digestion ruminal del heno (medido através de bolsas de dacron) em el ganado alimentado com caña de azúcar y heno de pangola. Trop. Anim. Prod. v. 3 n. 1, p. 9-11, 1978.

15 VALADARES FILHO, S. C. et al. Degradabilidade "in situ" da matéria seca e proteína bruta de vários alimentos em vacas em lactação. R. Soc. Bras. Zoot. v. 19 , n. 6, p. 512-522, 1990.

16 AROEIRA, L. J. M., Degradabilidade no rúmen e taxa de passagem da cana-de-açúcar mais uréia, farelo de algodão e do farelo de arroz em novilhos mestiços Europeu x Zebu. R Soc Bras Zoot, v. 22, n. 4, p. 552564,1993 b

17 AROEIRA, L. J. M; et al. Degradabilidade "in situ" dos nutrientes da cana-de-açúcar e do farelo de algodão em bovinos alimentados com farelo de algodão e canade-açúcar adicionada de três níveis de uréia. Arq Bras Med Vet Zoot, v. 45, n. 2, p. 221-223, 1993a.

18 NAUFEL, F.; et al. Estudo comparativo entre canade-açúcar e silagens de milho, sorgo e capim Napier na alimentação de vacas leiteiras. B. Indústr. Anim. v. 26, p. $9-22,1969$

19 SEAL, C. J.; PARKER, D. S. Effect of intraruminal prop ionic acid infusion on metabolism of mesentericand portal-drained viscera in growing sterrs fed a forage diet: I. Volatile fatty acids, glucose, and lactate. J. Anim. Sci. v. 72, n. 5, p.1325-1334, 1994.

20 PRIEGO, A.; WILSON, A.; SUTHERLAND, T. M. The effect of parameters of rumen fermentation, rumen volume and fluid flow rate of zebu bulls given chopped sugar cane supplemented with rice polishings or cassava root meal. Trop. Anim. Prod, v. 2. n. 3, p. 292-299, 1977.

21 VALDEZ, R. E. Rúmen function in cattle given sugar 
cane. Trop. Anim. Prod. v. 2, n. 3, p. 260-272, 1977. 22 SILVESTRE, R. N. A.; MACLEOD, N. A.; PRESTON, T. R. Voluntary intake and live weight gain of cattle given chopped sugar cane and molasses containing different concentrations of urea. Trop. Anim. Prod. v. 2, n. 1, p. 1-12, 1977.

23 RUIZ, G.; BOBADILLA, M.; HOVELL, F. D. D. The effect of wheat bran on rúmen fermentation, rúmen volume and fluid flow rate in zebu bulls fed chopped whole sugar cane. Trop. Anim. Prod. v. 3, n. 3, p. 247258, 1978.

24 PEIXOTO, A. M. A cana-de-açúcar como recurso forrageiro - In: GARDNER, A.L. e ALVIM, M. J. Manejo de pastagem, Empresa Brasileira de Pesquisa Agropecuária, 1985.

25 ORSKOV, W. R.; HOVELL, D. D.; MOULD, F. Uso de la tecnica de la bolsa de nylon para la valuacion de los alimentos. Prod. Anim. Trop. S. D, v. 5, n. 3, p.213233, 1980.

26 GOMES, F. P. Curso de Estatística Experimental. Piracicaba, SP: Fundação de Estudos Agrários Luiz de Queiroz, 1980.

27 NATIONAL RESEARCH COUNCIL. Nutrient requirements of sheep. Washinton, D.C.:NRC,1985.

28 ASSOCIATION OF OFFICIAL ANALYTICAL CHEMISTS. Official Methods of Analysis. 10 ed Washington D.C.: AOAC, 1980.

29 GOERING, H. K,; VAN SOEST, P.J. Forage fiber analysis. Washington: Agricultural Research Service, 1970. $379 p$.

30 RSKOV, E. R.; MCDONALD, I. The estimation of protein degradability in the rumen from incubation measurements weighted according to rate of passage. J.Agricultural Sci.. v. 92, p. 499-503, 1979.

31 HYDEN, S. A turbidometric method for the determination of higher polyethylene glycols in biological materials. D. Lantbr. Hogsk. Arbb., v. 22, p. 139, 1956.

32 ERWIN, E. S., MARCO, G. J, EMERY,E. M. Volatile fatty acid analysis of blood and rumen fluid by gas chromatography. J. Dairy Sci., v. 44, n. 9, p. 1768$1771,1961$.

33 STATISTICAL ANALYSIS SYSTEM. SAS user's guide: statistics, Cary: NC, 2001

34 MEHREZ, A. Z.; ORSKOV, E. R.; MCDONALD, I Rates of rumen fermentation in relation to amonia concentration. British J. Nutrition, v. 38, n. 3, p. 437 443, 1977.

35 AROEIRA, L. J. M., LOPES, F. C. F., DAYRELL, M. S. Degradabilidade de alguns alimentos no rúmen de vacas Holandes-Zebu. R Soc Bras Zoot, v. 25, n. 6, p. 11781186, 1996.
36 HUNGATE, R. E. The rumen and its microbes. New York: Academic Press, 1966. 533 p.

37 HUNGATE, R. E., REICHI, J.; PRINS, R. Parameters of rumen fermentation in a continuously fed sheep: evidence of a microbial rumination pool. Appl Microb. v. 22 , n. 6 , p. 1104-1113, 1971

38 LENG, R. A. PRESTON, T. R. Sugar cane for cattle production; present constraints, perspectives and research priorities. Trop Anim Prod, v. 1, n. 1, p1-26, 1976.

39 VEIRA, D. M. The role of ciliate protozoa in nutrition of the ruminant. J. Anim. Sci. v. 63, n. 5, p.15471560, 1989.

40 VEIRA, D. M.; IVAN, M.; JUI, P. Y. Rúmen ciliate protozoa: Effects on digestion in the stomach of sheep. J. Dairy Sci. v. 66, n. 5, p. 1015-1022, 1983. 